\title{
Quantitative description of characteristics of high-capacity channels in unconsolidated sandstone reservoirs using in situ production data
}

\author{
Wang Xuezhong1,4*, Wang Jianyong ${ }^{2}$, Wang Chuanfei ${ }^{3}$, Zeng Liufang ${ }^{4}$ \\ and Liu Xuewei ${ }^{5}$ \\ ${ }^{1}$ Xinjiang Exploration \& Production Center, Shengli Oilfield Company, Sinopec, Dongying, Shandong 257000, China \\ ${ }^{2}$ Sinopec, Beijing 100728, China \\ ${ }^{3}$ China University of Petroleum, Dongying, Shandong 257061, China \\ ${ }^{4}$ Gudong Oil Production Plant, Shengli Oilfield Company, Sinopec, Dongying, Shandong 257237, China \\ ${ }^{5}$ Institute of Porous Flow \& Fluid Mechanics, CNPC \& Chinese Academy of Sciences, Langfang, Hebei 065007, China \\ (C) China University of Petroleum (Beijing) and Springer-Verlag Berlin Heidelberg 2010
}

\begin{abstract}
Quantitative description of the high-capacity channels in unconsolidated sandstone reservoirs, into which water was injected to improve oil recovery, is a hot topic in the field of reservoir development. This paper presents a novel approach to describing quantitatively the characteristics of connected macropores in unconsolidated sandstone reservoirs using in situ production data. Based on physical simulation for formation mechanisms of high capacity channels and interwell tracer test data, a mathematical model was established to describe high-capacity channels by grey correlation theory, flow mechanism of fluid in porous media and reservoir engineering, and a program was developed to describe quantitatively the channel characteristics. The predicted results were consistent with field monitoring data $(80 \%)$, so this model could be economically and effectively used to identify high-capacity channels.
\end{abstract}

Key words: High-capacity channel, unconsolidated sandstone, quantitative description, physical simulation, interwell tracer, grey correlation theory

\section{Introduction}

High-capacity channels are secondary high-permeability bands formed by long-term erosion by water injected into unconsolidated sandstone reservoirs. These channels are easily formed in water controlled reservoirs, resulting in low waterflood efficiency and poor development performance (Fung, 1996; Hu et al, 2009; Khilar and Fogler, 1998; Wang, 2006). Quantitative description of high-capacity channels in unconsolidated sandstone reservoirs in which the oil was recovered by water flooding is a hot topic in the field of reservoir development. Seven description techniques; field observation, well logging, well testing, dynamic analysis, interwell monitoring with the potential method, physical simulation, and interwell tracer tests have been used to describe these channels (Alabert and Modot, 1992; Almeida and Cotta, 1996; Anisimov et al, 2009; Brigham and Delhganl, 1987; Liu, 2008; Lv et al, 2005; Seright and Lee, 1999; Zhang et al, 2001; Zhao et al, 1994). This paper proposes a novel approach to describing quantitatively the

*Corresponding author. email: wxzxlywlt@sina.com Received January 12, 2009 characteristics of high-capacity channels in unconsolidated sandstone reservoirs using in situ production data. Based on physical simulation for the formation mechanisms of high-capacity channels and interwell tracer test data, a mathematical model is established to describe parameters of these channels.

\section{Formation mechanisms of high-capacity channels in the Guantao Formation}

\subsection{Reservoir characteristics}

The Guantao Formation in the Gudong Oilfield, China is an unconsolidated sandstone reservoir with high permeability, which is dominated by fluvial sandstone facies. In this conventional heavy oil reservoir, water flooding was used to improve oil recovery. It was put into all-around production in 1986, and the cumulative oil production has reached about $7.39 \times 10^{7} \mathrm{t}$, and the annual oil production decreased to $2.0 \times 10^{6}$ t. The reservoir depth of the Guantao Formation ranges from $1,300 \mathrm{~m}$ to $1,400 \mathrm{~m}$ and the effective pay thickness is $6-10 \mathrm{~m}$. The average porosity and air permeability are $33 \%$ and 1.52 $\mu \mathrm{m}^{2}$, respectively. The horizontal to vertical permeability ratio 
is 5.0. The pore spaces in the reservoir are mainly connected macro-pores and pore throats with a radius of 1-6 $\mu \mathrm{m}$. The median grain diameter is about $0.12 \mathrm{~mm}$, indicating moderate sorting.

The reservoir is mainly dominated by fine silty sandstone, with a small amount of cementing material (including shale and contact cement). The content of clay materials is $9.4 \%$, in which the montmorillonite and illite, which are easy to swell when encountering water, account for $62 \%$. The reservoir is water-wet, water-sensitive, salt-sensitive, weak acid-sensitive, and alkali-sensitive. The viscosity of crude oil under standard conditions is $450-3,000 \mathrm{mPa} \cdot \mathrm{s}$, while it reduces to 50 $130 \mathrm{mPa} \cdot \mathrm{s}$ under the reservoir conditions. In addition, the viscosity of formation water is about $0.44 \mathrm{mPa} \cdot \mathrm{s}$. Owing to low natural energy, water is injected into the reservoir to maintain the reservoir pressure.

During the development of the Guantao Formation, sand production has become one of the serious operational problems in a large number of production wells, with a high sand production rate and large grain size. Sand wells account for $82 \%$ of all the oil producing wells, and $5 \mathrm{~m}^{3}$ of sand was removed from a single well. According to the sand cleanout data from the gathering tanks, the sand production rate increased from $2.8 \mathrm{~m}^{3}$ to $59.6 \mathrm{~m}^{3}$ per $10^{4}$ tons of oil. Moreover, the sand diameter increased from $0.13 \mathrm{~mm}$ to 0.16 $\mathrm{mm}$. The well test results of the Gudong 2-13-47 well showed that the proportion of produced load bearing solids increased significantly and the formation structure was severely damaged when the fluid-production intensity exceeded 14.1 $\mathrm{t} /(\mathrm{d} \cdot \mathrm{m})$. It was also found that casing damage occurred in 386 wells and at the same time cross flow was very severe along the high-permeability formations, leading to low waterflood efficiency.

\subsection{High-capacity channels monitored with interwell tracer tests}

Interwell tracer monitoring is a technique in which tracer is added to an injection well to determine the fluid paths, thus the high-capacity channels can be identified or detected (Brigham and Delhganl, 1987; Deng and Horne, 1995). The tracer performance sheds light on the heterogeneity features of oil-bearing formation and the distribution of injection fluid in the formation. Interwell tracer tests can be used to determine the characteristics of the oil-bearing formation and the relationship between production and injection wells on a large scale. It is taken as an important means to characterize the high-capacity channels (Anisimov et al, 2009; DattaGupta et al, 2007; Walkup Jr and Horne, 1985). Tracer radioisotopes can be measured and recorded automatically at the well-head in routine production without needing any separate water sampling. Hence, this technology is widely used to detect connected macro pores between producer and injector. For example, connected macro pores and pore throats exist in well group 7-32-266 in the Gudong Oilfield, China. Thirtyone well groups were monitored with the interwell isotopic tritiated water tracer method in the Guantao Formation. The permeability from well logging data ranged from 0.44 to $6.39 \mu \mathrm{m}^{2}$, with an average of $1.58 \mu \mathrm{m}^{2}$. The thickness of oil- bearing formation into which water was injected was 6.2$30.2 \mathrm{~m}$, with an average of $15.7 \mathrm{~m}$. The injection-production well spacing was $170-490 \mathrm{~m}$, with an average of $266 \mathrm{~m}$. The production thickness in a single well was $4.7-29 \mathrm{~m}$, with an average of $11.3 \mathrm{~m}$.

Of all the 170 oil production wells, there were 59 wells where the tracers were detected (Table 1). Of the tracerdetected wells, high-capacity channels were detected in the same layer among (or around) 51 wells, accounting for $86 \%$; and interlayer cross flow was detected in the remaining 8 wells, accounting for $14 \%$. The flow rate was $1.0-64.7 \mathrm{~m} /$ $\mathrm{h}$, while the flow rate along the high-capacity channels was generally more than $6 \mathrm{~m} / \mathrm{h}$.

The average flow rates in the Guantao Formation were $1.08,1.58$, and $6.02 \mathrm{~m} / \mathrm{h}$, respectively in the initial stage, middle stage, and present stage of water injection development. The average flow rate at the present stage was 5 times higher than that in the initial stage (Table 2).

\subsection{Study of high-capacity channel formation}

Physical simulation was conducted in a sand pack model to study the formation mechanisms of high-capacity channels (Liu, 2008; Lv et al, 2005). Research results showed that the formation of high-capacity channels, which was closely related to sedimentary characteristics, reservoir physical properties, and development methods, were mainly due to the high viscosity of fluids, high permeability of reservoir, and sand production. The factors dominating the formation of connected macro pores are reservoir permeability, cementing strength, liquid viscosity, and injection-production intensity (Liu et al, 2003). Sand production in oil formations and particle migration, leading to a significant change in reservoir porosity, permeability, and shale content, are the major causes for high-capacity channel formation.

Flow characteristics of fluids in high-capacity channels were drawn from laboratory experiments:

1) Characteristics of liquid production. Before highcapacity channels were formed, the liquid production was kept at a stable level; but the liquid production increased greatly after channel formation.

2) Characteristics of liquid productivity index. Before high-capacity channels were formed, the liquid productivity index changed slightly; but the liquid productivity index increased significantly after channel formation.

3) Characteristics of water injection. Before highcapacity channels were formed, the water injection rate was held constant, but its value increased greatly after channel formation.

4) Characteristics of water injectivity index. Before high-capacity channels were formed, water injectivity index changed slightly, but after high-capacity channel formation, water injectivity index increased greatly.

Both the liquid productivity index and water injectivity index reflect the variation in reservoir permeability.

The conclusion drawn from laboratory experiments is consistent with the field data (low reservoir pressure, low threshold pressure, high water injectivity index, and strong water absorption capacity of high-capacity reservoirs). 
Table 1 High-capacity channels monitored with the interwell tracer tests in the Guantao Formation

\begin{tabular}{|c|c|c|c|c|}
\hline \multirow[b]{2}{*}{ Injection well } & \multicolumn{2}{|c|}{ Major high-capacity channels } & \multicolumn{2}{|c|}{ Secondary high-capacity channels } \\
\hline & $\begin{array}{l}\text { Corresponding } \\
\text { production well }\end{array}$ & $\begin{array}{c}\text { Flow rate } \\
\mathrm{m} / \mathrm{h}\end{array}$ & $\begin{array}{l}\text { Corresponding } \\
\text { production well }\end{array}$ & $\begin{array}{c}\text { Flow rate } \\
\mathrm{m} / \mathrm{h}\end{array}$ \\
\hline $6-32-515$ & $6-33-2514$ & 0.83 & $6-31-494$ & 0.06 \\
\hline $7-32-266$ & $7-32-4246$ & 9.54 & $7-31-4246$ & 6.12 \\
\hline $7-27-226$ & $7-26-4226$ & 41.7 & $7-27-4206$ & 15.2 \\
\hline $7-47-336$ & $7-46-326$ & 5.33 & $7-46-335$ & 0.48 \\
\hline $7-28-4326$ & $7-27-306$ & 5.3 & - & - \\
\hline $3-16-34$ & $3-18-34$ & 0.65 & $3-17-133$ & 0.52 \\
\hline $7-26-226$ & $7-27-4206$ & 64.7 & $7-26-4226$ & 41.7 \\
\hline $7-42-266$ & $7-43-285$ & 0.76 & - & - \\
\hline $8-22-16$ & $8-24-2014$ & 15.83 & $8-24-16$ & 13.33 \\
\hline $7-31-266$ & $7-32-286$ & 1.20 & - & - \\
\hline $7-35-306$ & $7-35-2306$ & 0.13 & - & - \\
\hline $3-12-1026$ & $4-13-23$ & 3.02 & $3-15-26$ & 2.72 \\
\hline $7-43-105$ & $7-43-126$ & 0.29 & - & - \\
\hline $7-34-4326$ & $7-32-4326$ & 0.89 & - & - \\
\hline $7-23-22$ & $7-21 \times 221$ & 1.54 & $7-21-22$ & 1.31 \\
\hline $7-33-286$ & $7-33-4266$ & 2.00 & $7-32-286$ & 1.09 \\
\hline $7-48-326$ & $7-46-335$ & 0.66 & $7-46-326$ & 0.49 \\
\hline $7-22-235$ & $7-24-235$ & 6.36 & $7-24 N 215$ & 2.82 \\
\hline $7-47-336$ & $7-46-326$ & 4.44 & $7-46-335$ & 0.42 \\
\hline $7-39-346$ & $7-37-354$ & 2.34 & - & - \\
\hline $8-22-2014$ & $8-20-2014$ & 5.62 & $8-21-2014$ & 0.86 \\
\hline $7-28-5195$ & $7-26 \mathrm{~N} 5206$ & 2.28 & - & - \\
\hline
\end{tabular}

Table 2 A comparison of flow rate in high-capacity channels in different development stages in the Guantao Formation

\begin{tabular}{ccc}
\hline Development stage & $\begin{array}{c}\text { Range of flow rate } \\
\mathrm{m} / \mathrm{h}\end{array}$ & $\begin{array}{c}\text { Average flow rate } \\
\mathrm{m} / \mathrm{h}\end{array}$ \\
\hline Initial stage & $0.54-1.62$ & 1.08 \\
Middle stage & $1.04-2.09$ & 1.58 \\
Later stage & $1.05-64.7$ & 6.02 \\
\hline
\end{tabular}

\section{Approach of quantitative description for high-capacity channels}

Based on laboratory experiment and the interwell isotopic tracer tests, we proposed an approach to describing quantitatively the characteristics of high-capacity channels using in situ production data.

\subsection{High-capacity channel identification with grey correlation theory}

In the course of high permeability, unconsolidated sandstone reservoir development, the correlation of injection and production wells was rapid pressure response. Especially after the high-capacity channels were formed, the connectivity between production and injection wells was greatly enhanced and the pressure response time between production and injection wells became much shorter (Brigham and Delhganl, 1987; Datta-Gupta et al, 2007). The connectivity between production and injection wells could be estimated by calculating the correlation between liquid productivity index and water injectivity index (Alabert and Modot, 1992; Yousef et al, 2005) and then the high-capacity channels identified by means of grey correlation theory.

Grey correlation analysis is an approach to searching for the main correlations of all factors in the system and selecting the important factor that influences the target value (Deng, 1987). Quantitative description and comparison for the development and variation trends of the system is the foundation of analysis, prediction and decision of the grey system. It includes the selection of mother-series and subseries, the calculations of the degree of correlation, correlation order and correlation matrix. Through grey correlation analysis, we can carry out the correlation calculation of the liquid production of one well and the surrounding wells to obtain quantitative corresponding correlation so as to help us judge. For example, we can take grey correlation degree of more than 0.5 as a sign of the existence of substantial highcapacity channels between injecion and production wells. The pseudo water injectivity index is the ratio of daily waterinjection rate to surface pressure. The pseudo water injectivity 
index is treated as mother-series and the liquid productivity index is treated as sub-series when grey correlation theory is used to identify high-capacity channels. The liquid productivity index is affected by the pseudo water injectivity index, and then the pseudo water injectivity index is an active factor while the liquid productivity index is a passive factor. Correlation degree is between 0 and 1 . If the correlation degree of sub-series factors and mother-series factors is more close to 1 , it shows that their correlation is closer or rather the influence of sub-factors on mother-factor is bigger, and vice versa.

\subsection{Calculation of high-capacity channel parameters}

Based on field experience, the following assumptions were made for an injector-producer pair: After the highcapacity channels are formed, the oil initially trapped is totally displaced from these macro-pores and pore throats and then the residual oil saturation is zero. The water injected into the formation preferentially flows along the high-capacity channels. The volume of macro-pore and pore throats is calculated from the difference between theoretical output and actual output. And then the permeability of the interconnected macro-pores is calculated from Darcy equation. Finally, the radius of these macro-pores is computed from the permeability-porosity equation.

1) Calculate the theoretical water-oil ratio based on oil viscosity, water viscosity, and effective permeability

$$
x=\frac{k_{\mathrm{w}} \mu_{0}}{k_{0} \mu_{\mathrm{w}}}
$$

2) Calculate the water production from the zones, where the high-capacity flow channels are not formed, according to theoretical water-oil ratio, and actual oil production

$$
q_{\mathrm{w} 1}=q_{0} x
$$

3) Calculate the water production from the zones where the high-capacity flow channels are formed

$$
q_{\mathrm{w} 2}=q_{\mathrm{w}}-q_{\mathrm{w} 1}
$$

4) Calculate the theoretical water production from the whole zones before the high-capacity flow channels are formed

$$
q_{\mathrm{wlt}}=\frac{2 \pi k_{\mathrm{w}} h \mathrm{~d} p}{\mu_{\mathrm{w}} \ln \frac{r_{\mathrm{e}}}{r_{\mathrm{w}}}}
$$

5) Calculate the volume of macroscopic pore space

$$
V_{\mathrm{d}}=V\left(1-\frac{q_{\mathrm{w} 1}}{q_{\mathrm{w} t \mathrm{t}}}\right)
$$

6) Calculate the permeability due to macroscopic pore space

$$
K_{\mathrm{d}}=\frac{q_{\mathrm{w}} \mu_{\mathrm{w}} l^{2}}{V_{\mathrm{d}} \mathrm{d} p}
$$

7) Calculate the radius of macroscopic pore space

$$
r_{\mathrm{d}}=\left(\frac{8 K_{\mathrm{d}} \tau^{2}}{\varphi}\right)^{0.5}
$$

where $x$ is the theoretical water-oil ratio; $\mathrm{d} p$ is the pressure drop, $\mathrm{MPa} ; h$ is the thickness of the oil-bearing formation, $\mathrm{m} ; K_{\mathrm{d}}$ is the permeability due to connected macropore space, $\mu \mathrm{m}^{2} ; K_{0}$ is the oil effective permeability, $\mu \mathrm{m}^{2} ; K_{\mathrm{w}}$ is the water effective permeability, $\mu \mathrm{m}^{2} ; \mu_{0}$ is the oil viscosity under reservoir conditions, $\mathrm{mPa} \cdot \mathrm{s} ; \mu_{\mathrm{w}}$ is the water viscosity under reservoir conditions, $\mathrm{mPa} \cdot \mathrm{s} ; q_{0}$ is the actual oil production, $\mathrm{t} / \mathrm{d} ; q_{\mathrm{w}}$ is the actual water production, $\mathrm{m}^{3} / \mathrm{d} ; l$ is the well array width, $m ; q_{w 1}$ is the water production from the zone where high-capacity flow channels are formed, $t /$ $\mathrm{d} ; q_{\mathrm{w} 2}$ is the water production from the zone where no highcapacity flow channels are formed, $\mathrm{t} / \mathrm{d} ; q_{\mathrm{wlt}}$ is the theoretical water production from a single well before high-capacity flow channels are formed, $\mathrm{t} / \mathrm{d} ; r_{\mathrm{d}}$ is the average radius of macroscopic pore space, $\mu \mathrm{m} ; r_{\mathrm{e}}$ is the radius of area controlled by a single well, $\mathrm{m} ; r_{\mathrm{w}}$ is the wellbore radius, $\mathrm{m} ; V$ is the pore volume controlled by a single well, $\mathrm{m}^{3} ; V_{\mathrm{d}}$ is the volume of macroscopic pore space, $\mathrm{m}^{3}$; fraction; $\tau$ is the porosity, $\%$; $\tau$ is the tortuosity, fraction.

For commingled multizone production that is widely used in the oilfield development, the initial permeability may be different among each layer. The first step is to calculate the "split production" of commingled production wells and commingled injection to transfer the commingled production of multilayers into single layer production to calculate the high-capacity channel parameters. At the same time, we propose moderately enlarging the proportion of single production wells and single injection wells to make the output and pressure data more accurate, which contributes to improving the calculation precision of high-capacity channel parameters.

On the basis of above, a corresponding quantitative description program was developed.

\subsection{Verification and application of the description method}

The program developed was applied to 227 wells drilled in the $\mathrm{Ng}^{3+4}$ unit in the seventh region of the Gudong Oilfield. Analytical results showed that high-permeability paths existed in 120 wells, accounting for $53 \%$. The calculated highcapacity channel permeability was $8-80 \mu \mathrm{m}^{2}$, with an average of about $10 \mu \mathrm{m}^{2}$, which was 6 times larger than the initial value of $1.5 \mu^{2}$. The calculated radius of macropores was 12-60 $\mu \mathrm{m}$, with an average of about $20 \mu \mathrm{m}$, which is 2 times larger than the initial pore radius $(6 \mu \mathrm{m})$ (Table 3$)$. Interwell tracer tests and variable density logging implemented in 32 wells in the Gudong Oilfield indicated that the accordance of interpretation results was more than $80 \%$.

The calculated results from the model showed highcapacity channels existed between the 7-27-226 well and 7-26-4226 well as well as between the 7-27-226 well and 7-27-4206 well. The correlation degrees were 0.700 and 0.639 ; the high-capacity channel permeabilities were 16.5 and 9.8 $\mu \mathrm{m}^{2}$. Interwell tracer tests were conducted in this well group. As a result, tracer was detected in 7-26-4226 well and 7-274206 well, in which the flow rate were 41.7 and $15.2 \mathrm{~m} / \mathrm{h}$, respectively. This verified the conclusion drawn from the description model of high-capacity channels. 
Table 3 A comparison of interpretation results from the model developed and tracer tests conducted in the $\mathrm{Ng} 6^{3+4}$ unit in the Gudong Oilfield

\begin{tabular}{cccccc}
\hline Injection well & $\begin{array}{c}\text { Corresponding } \\
\text { production well }\end{array}$ & Correlation degree & $\begin{array}{c}\text { High-capacity } \\
\text { channel permeability } \\
\mu \mathrm{m}^{2}\end{array}$ & $\begin{array}{c}\text { Radius } \\
\text { of macropores } \\
\mu \mathrm{m}\end{array}$ & $\begin{array}{c}\text { Flow rate in } \\
\text { the porous media } \\
\mathrm{m} / \mathrm{h}\end{array}$ \\
\hline $7-27-226$ & $7-27-4206$ & 0.68 & 9.8 & 13.53 & 15.2 \\
$7-28-266$ & $7-28-4246$ & 0.68 & 87.8 & 483 & 54.2 \\
$7-26-246$ & $7-26-4226$ & 0.95 & 82.4 & 148 & 82.5 \\
$7-33-314$ & $7-32-2306$ & 0.84 & 35.4 & 97 & 71.4 \\
\hline
\end{tabular}

At present, the flow rate of fluids in the porous medium was more than $6 \mathrm{~m} / \mathrm{h}$ and the permeability was about 20 $\mu \mathrm{m}^{2}$. In general, the thickness of the layer containing highcapacity channels (obtained by means of core observation) was only several centimeters, accounting for $1 \%-8 \%$ of the thickness of the formation into which water was injected, but the water adsorption accounted for over $90 \%$. Based on the classification criteria for high-capacity channels proposed by Li and Chen (2002), the high-capacity channels existed in different watered-out zones in the Guantao Formation were classified and evaluated (Table 4).

Since 2005, the model developed for describing macropores combined with monitoring data was used to analyze high-capacity channels. 104 stimulations were implemented in production or injection wells, which were effective in 98 wells (94\%). Up to now, cumulative oil production has reached $7.6 \times 10^{4} \mathrm{t}$ (Table 5).

Table 4 Characteristics of macropores and pore throats developed in different waterflooded zones in the Guantao Formation

\begin{tabular}{|c|c|c|c|c|}
\hline \multirow{2}{*}{ Category } & \multirow{2}{*}{$\begin{array}{c}\text { Proportion } \\
\%\end{array}$} & \multirow{2}{*}{$\begin{array}{c}\text { Thickness } \\
\mathrm{m}\end{array}$} & \multicolumn{2}{|c|}{ Flow rate, $\mathrm{m} / \mathrm{h}$} \\
\hline & & & Range & Average \\
\hline Waterflooded zones with high permeability & 51 & 11.1 & $0.11-1.58$ & 0.61 \\
\hline Waterflooded zones with high-capacity channels & 29 & 10.4 & $1.66-6.88$ & 3.82 \\
\hline Waterflooded zones with giant high-capacity channels & 20 & 13.1 & $6.98-15.80$ & 12.53 \\
\hline
\end{tabular}

Table 5 Production well performances before and after stimulations (water plugging) performed in high-capacity channels in the Guantao Formation

\begin{tabular}{|c|c|c|c|c|c|c|c|c|c|}
\hline \multirow[b]{2}{*}{ Well } & \multirow{2}{*}{$\begin{array}{c}K \\
\mu \mathrm{m}^{2}\end{array}$} & \multirow{2}{*}{$\begin{array}{c}K_{\mathrm{d}} \\
\mu \mathrm{m}^{2}\end{array}$} & \multirow{2}{*}{$\begin{array}{r}r_{\mathrm{d}} \\
\mu \mathrm{m}\end{array}$} & \multicolumn{3}{|c|}{ Before stimulation treatment } & \multicolumn{3}{|c|}{ After stimulation treatment } \\
\hline & & & & $\begin{array}{l}\text { Liquid production } \\
\text { rate, } t / d\end{array}$ & $\begin{array}{l}\text { Oil production } \\
\text { rate, } t / d\end{array}$ & $\begin{array}{c}\text { Water cut } \\
\%\end{array}$ & $\begin{array}{l}\text { Liquid production } \\
\text { rate, } t / d\end{array}$ & $\begin{array}{l}\text { Oil production } \\
\text { rate, } \mathrm{t} / \mathrm{d}\end{array}$ & $\begin{array}{c}\text { Water cut } \\
\%\end{array}$ \\
\hline $7-32-406$ & 2.13 & 4.83 & 22.0 & 0 & - & - & 12.8 & 1.5 & 88 \\
\hline $7-39-246$ & 1.85 & 2.80 & 16.7 & 145 & 1.5 & 98.9 & 61.8 & 2.4 & 96.1 \\
\hline $7-31-4166$ & 0.96 & 3.01 & 17.4 & 109 & 1.9 & 98.2 & 70.1 & 2.4 & 96.6 \\
\hline $7-38-4254$ & 2.98 & 6.90 & 26.3 & 43.4 & 1.2 & 97.2 & 124 & 1.4 & 98.9 \\
\hline $7-29-4236$ & 1.38 & 12.00 & 27.5 & 9.3 & 0.6 & 93.4 & 22.8 & 3.4 & 84.8 \\
\hline $7-36-255$ & 0.55 & 1.60 & 12.4 & 47.3 & 2.7 & 94.1 & 36.1 & 7.4 & 79.5 \\
\hline $7-39-215$ & 0.81 & 3.20 & 17.4 & 0 & - & - & 72.4 & 2.3 & 96.8 \\
\hline $7-38-186$ & 0.95 & 11.45 & 33.8 & 60 & 0.6 & 99 & 46.4 & 2.2 & 95.3 \\
\hline $7-24-3366$ & 4.04 & 14.10 & 37.5 & 266 & 1 & 99.6 & 183 & 1.3 & 99.3 \\
\hline $7-26-186$ & 0.21 & 1.50 & 12.3 & 0 & - & - & 68.3 & 2.6 & 96.2 \\
\hline $7-25 \mathrm{~N} 186$ & 0.74 & 2.33 & 16.3 & 211 & 3.8 & 98.2 & 24 & 16.4 & 31.7 \\
\hline $7-24-206$ & 1.99 & 8.79 & 29.7 & 125 & 3.3 & 97.4 & 52.7 & 12.2 & 76.9 \\
\hline $7-32-286$ & 1.50 & 15.09 & 38.8 & 83.8 & 3.8 & 95.4 & 80.1 & 19.1 & 76.2 \\
\hline $7-32-4326$ & 0.52 & 1.63 & 18.9 & 106 & 1.3 & 98.8 & 88.6 & 10 & 88.7 \\
\hline $7-32-4286$ & 0.53 & 56.50 & 75.2 & 109 & 2.1 & 98.0 & 39.4 & 5.5 & 85.9 \\
\hline $7-35-4286$ & 1.02 & 5.29 & 23.0 & 111 & 1.9 & 98.3 & 111 & 6.7 & 94.0 \\
\hline $7-27-174$ & 1.50 & 3.10 & 17.6 & 151 & 2.7 & 98.2 & 61.6 & 3.3 & 94.5 \\
\hline $7-31-394$ & 2.03 & 7.23 & 26.8 & 85.5 & 2.1 & 97.5 & 70 & 8.7 & 87.6 \\
\hline $\begin{array}{l}7-28- \\
4246\end{array}$ & 0.42 & 1.76 & 13.3 & 159 & 1.7 & 98.9 & 125 & 4.4 & 96.5 \\
\hline $\begin{array}{c}7-26- \\
4226\end{array}$ & 1.37 & 50.53 & 67.9 & 173 & 3 & 98.3 & 89.9 & 17.4 & 80.6 \\
\hline Total & - & - & - & 1994 & 35.2 & 98.2 & 1440 & 131 & 90.9 \\
\hline
\end{tabular}




\section{Conclusions}

Aiming at the difficult problem of quantitative description for high-capacity channels in unconsolidated sandstone reservoirs, this paper proposes a novel approach to describing quantitatively high-capacity channels in unconsolidated sandstone reservoirs developed by water flooding using in situ production data. Based on physical simulation for highcapacity channel formation mechanism and interwell tracer monitoring data, a mathematical model was established to describe parameters of high-capacity c:hannels through grey correlation theory, flow mechanisms in porous media and reservoir engineering. After this method was applied in the Gudong Oilfield, it is verified that the coincidence rate was over $80 \%$ and it has achieved high-capacity channel identification economically and effectively to lay foundation for enhanced oil recovery.

\section{References}

Alabert F G and Modot V. Stochastic models of reservoir heterogeneity: impact on connectivity and average permeabilities. Paper SPE 24893 presented at SPE Annual Technical Conference and Exhibition held in Washington, DC, USA, 4-7 October 1992

Almeida A R and Cotta R M. Analytical solution of the tracer equation for the homogeneous five-spot problem. SPE Journal. 1996. 1(1): 31-38 (Paper SPE 29218)

Anisimov L A, Kilyakov V N, Vorontsova I V, et al. The use of tracers for reservoir characterization. Paper SPE 118862 presented at SPE Middle East Oil \& Gas Show and Conference held in the Bahrain International Exhibition Centre, Kingdom of Bahrain, 15-18 March 2009

Brigham W E and Delhganl M A. Tracer testing for reservoir description. Journal of Petroleum Technology. 1987. 39(5): 519-527

Datta-Gupta A, Vasco D W and Long J C S. On the sensitivity and spatial resolution of transient pressure and tracer data for heterogeneity characterization. SPE Formation Evaluation. 2007. 12(2): 137-144

Deng J L. Basic Method of Grey System. Shanghai: Huazhong University of Science and Technology Press. 1987. 101-132 (in Chinese)

Deng X F and Horne R. Description of heterogeneous reservoir using tracer and pressure data simultaneously. Paper SPE 30590 presented at SPE Annual Technical Conference \& Exhibition held in Dallas,
USA, 22-25 October 1995

Fung L S K. Modeling of cavity stability and sand production in heavy oil reservoirs. Journal of Canada Petroleum Technology. 1996. 35(2): 47-52.

Hu S Y, Zhang L H, Yao H S, et al. Method for simulating formation of water channels in unconsolidated sandstone reservoirs during waterflooding. Journal of Liaoning Technical University (Natural Science). 2009. 28(4): 100-103 (in Chinese)

Khilar K C and Fogler H S. Migrations of Fines in Porous Media. Dordrecht: Kluwer Academic Publishers, 1998.

Li S X and Chen Y M. Morphological characteristics of tracer production curves. Petroleum Geology and Recovery Efficiency. 2002. 9(2): 6667 (in Chinese)

Liu J L. Simulation experiments of the formation process of high capacity channels in a sand pack model with glass plate. Petroleum Geology and Recovery Efficiency. 2008. 15(5): 95-97 (in Chinese)

Liu Y T, Sun B L and Yu Y S. Fuzzy identification and quantitative calculation method for big pore throat. Oil Drilling \& Production Technology. 2003. 25(5): 54-59 (in Chinese)

Lv G Z, Zhang J Q and Sun Y H. Physical simulation of sand production mechanism in unconsolidated sandstone reservoirs. Journal of Basic Science and Engineering. 2005. 13(3): 284-290 (in Chinese)

Seright R S and Lee R L. Gel treatment for reducing channeling in naturally fractured reservoirs. SPE Production \& Facilities. 1999. 14(4): 269-276

Walkup Jr G W and Horne R N. Characterization of tracer retention processes and their effect on tracer transport in fractured geothermal reservoirs. Paper SPE 13610 presented at SPE California Regional Meeting held in Bakersfield, California, 27-29 March 1985

Wang X Z. High-capacity channel features of the high water-cut stage in the Gudong Oilfield. China Offshore Oil and Gas (Geology). 2006. 10(1): 101-105 (in Chinese)

Yousef A A, Gentil P, Jensen J L, et al. A capacitance model to infer interwell connectivity from production and injection rate fluctuations. Paper SPE 95322 presented at SPE Annual Technical Conference and Exhibition held in Dallas, Texas, USA, 9-12 October, 2005

Zhang Y, Jiang R Z and Zheng X Q. Analysis technology of interwell tracer. Journal of the University of Petroleum, China. 2001. 25(2): 76-78 (in Chinese)

Zhao F L, Zhang G C, Sun M Q, et al. Studies of channel plugging in a reservoir by using clay as a profile control agent in a double-fluid method. Acta Petrolei Sinica. 1994. 15(1): 56-64 (in Chinese)

(Edited by Sun Yanhua) 